\title{
Biological comparison of ovarian cancer resistant cell lines to cisplatin and Taxol by two different administrations
}

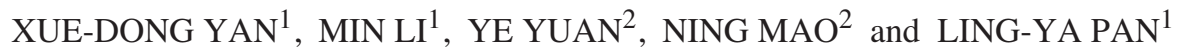 \\ ${ }^{1}$ Department of Obstetrics and Gynecology, Chinese Academy of Medical Sciences and \\ Peking Union Medical College Hospital, Beijing 100730; ${ }^{2}$ Department of Cell Biology, \\ Institute of Basic Medical Sciences, Beijing 100850, P.R. China
}

Received November 3, 2006; Accepted December 5, 2006

\begin{abstract}
Drug resistance is one of the major obstacles to chemotherapy of ovarian cancer. Studies with cell lines can serve as an initial screen for agents that might modulate drug resistance. To establish more appropriate models of drug resistance and explore whether the differences exist in the different drug resistant sublines selected by different treatments, we induced SKOV3 cell line using cisplatin (CDDP) and Taxol over a period of 16 months by the pulse (SKOV3/CDDP-P and SKOV3/Taxol-P) and intermittent incremental (SKOV3/CDDP-80 and SKOV3/Taxol-25) method, respectively. The resistant phenotype of the four resistant sublines, SKOV3/CDDP-P, SKOV3/CDDP-80, SKOV3/Taxol-P and SKOV3/Taxol-25, was very stable and the resistance index was 4.12, 11.50, 261.98 and 622.76, respectively. In cell morphology, the cells from pulse treatment had remarkable changes compared with the cells from intermittent incremental treatment. SKOV3/CDDP-80 and SKOV3/Taxol-P grew more slowly than SKOV3/CDDP-P and SKOV3/Taxol-25. Multidrug resistance gene 1, multidrug resistance protein 1 , lung resistance protein and glutathione S-transferase pi mRNA expression of SKOV3/CDDP-P and SKOV3/Taxol-25 had greater changes than that of SKOV3/ CDDP-80 and SKOV3/Taxol-P. The results suggest there are great differences between the resistant cell lines resulting from pulse and intermittent incremental method. The resistant cells selected by the intermittent method were more resistant than the cells selected by the pulse method. The two resistant sublines selected by the pulse method may serve as appropriate models for the study of mechanisms of drug resistance in ovarian cancer.
\end{abstract}

Correspondence to: Professor Ling-Ya Pan, Department of Obstetrics and Gynecology, Peking Union Medical College Hospital, 1 Shuai Fu Yuan, Beijing 100730, P.R. China

E-mail: lingyapan@hotmail.com

Key words: ovarian cancer, cisplatin, Taxol, drug resistance, cell line

\section{Introduction}

Ovarian cancer is the leading cause of gynecological cancer mortality. Despite the fact that first-line chemotherapy is effective in reducing tumor burden following optimal cytoreductive surgery, the 5-year survival rate for stage III and IV disease is $\sim 20-30 \%$ (1). One of the major reasons for the low 5-year survival rate is the appearance of drug resistance. The combination chemotherapy of CDDP and Taxol has been confirmed as the first-line therapeutic protocol via long-term prospective studies of clinical trials and resistance to anti-tumor drugs has been well defined in ovarian cancer (2). The elucidation of drug resistant mechanisms is insufficient to overcome clinical resistance.

Many resistant tumor cells in humans are gradually acquired during chemotherapy. The resistant cell lines, selected by exposure to anti-tumor agents, have been valuable tools for the illumination of the factors underlying drug resistance since the first induced resistant cell lines in vitro were used by stepwise augmentation treatment 40 years ago. Until now the most common method of establishing resistant cell lines is to use increasing continuous administration (3) and low-dosage intermittent incremental inducement (4) with various and inconsistent dosages. The two methods are significantly different from clinical chemotherapy, in which a pulse protocol with certain interval is commonly adopted. The pulse treatment in previous studies was seldom used compared with the two above methods $(5,6)$. Various dosages were selected for the inducement of the resistant cells in different studies. The usage of the resistant cell lines has greatly promoted the understanding of mechanisms of resistance and drug resistance-associated genes, such as multidrug resistance gene 1 (MDR1) and glutathione S-transferase pi (GST-pi) $(7,8)$. However, the crucial problem existing in the present studies is that studies with cells in culture might not always mirror the situation in clinical tumors and contradictory evidence concerning the mechanisms of drug resistance have been reported (9-12). The situation may be due, at least in part, to the difference of the resistant cells selected by dissimilar approach and a failure in combination of the laboratory and the clinic. In view to the previously inconsistent evidence, it is very possible that different mechanisms are involved in drug 
resistance selected by different approaches and it is important to establish standard resistant models similar to the clinic for understanding of mechanisms of drug resistance and reversal of the clinical chemoresistance.

In the present study, we induced SKOV3 using CDDP and Taxol by imitating the pattern of clinical chemotherapy (pulse treatment) and the conventional method (low-dosage intermittent incremental inducement), and investigated the effects of different administrations on drug resistance for the first time. We found the resistant phenotype of the cells selected by the pulse method and low-dosage intermittent method was very stable. The resistant cells selected by the intermittent method were more resistant than the cells selected by the pulse method. There were many differences between the cells selected by the two different methods, indicating different mechanisms of drug resistance may exist in the cells induced by different methods. Considering the pulse method is similar to the clinic, the two resistant sublines selected by the pulse method may serve as appropriate models for the study of mechanisms of drug resistance in ovarian cancer.

\section{Materials and methods}

Drugs. CDDP was purchased from F.H. Faulding \& Co. Ltd. (Melbourne, Victoria, Australia) and stored at a concentration of $3.33 \mathrm{mM}$ at room temperature. Taxol was obtained from Bristol-Myers Squibb Co. (Princeton, NJ, USA) and stored at a concentration of $10 \mathrm{nM}$ diluted in DMEM at room temperature.

Cell lines and culture conditions. SKOV3 is a human epithelial ovarian cancer cell line obtained from Cell Culture Center, Institute of Basic Medical Sciences, Chinese Academy of Medical Sciences. The SKOV3/CDDP-P (SD-P) was generated by selecting SKOV3 cells for growth with CDDP at pulse treatment of $100 \mu \mathrm{M}$ for $2 \mathrm{~h}$, and then the treated cells grew in drug-free medium. Another treatment was not administered until the cells were in exponential phase. The cells were induced 20 times in $100 \mu \mathrm{M}$ CDDP. SKOV3/CDDP-80 (SD80 ) was intermittently selected by small dosage of CDDP at $10,20,40$ and $80 \mu \mathrm{M}$ and 10 times each dosage. The cells were incubated in CDDP-containing medium for $48 \mathrm{~h}$ and were subjected to another drug treatment when the cells became confluent. Similarly, SKOV3/Taxol-P (ST-P) was induced by 20 pulse treatments with $2.5 \mu \mathrm{M}$ Taxol for $1 \mathrm{~h}$ each time. SKOV3/Taxol-25 (ST-25) was selected by intermittently growing in small dosage of Taxol at $10 \mathrm{nM}, 15 \mathrm{nM}$ and $25 \mathrm{nM}$ for $24 \mathrm{~h}$ and 10 times each dosage. The four resistant subclones were established over a period of 16 months. All the cells were maintained in Dulbecco's modified Eagle's medium (DMEM) containing $10 \%$ fetal calf serum, $100 \mathrm{U} / \mathrm{ml}$ penicillin and streptomycin. Cells were kept at $37^{\circ} \mathrm{C}$ in a humidified atmosphere of $5 \% \mathrm{CO}_{2}$ and $95 \%$ air. These cell lines grew in monolayers and were passaged when cultures were $70-80 \%$ confluent. No experiments were performd until all the cells had been maintained in medium-free drugs for 2 months.

Drug sensitivity assay. Cells were harvested from exponential phase and digested using $0.25 \%$ trypsin-EDTA. Single-cell suspensions were prepared. Cells were counted using a hemo- cytometer and then dispersed within 96-well microtiter plates. Six duplicate wells were used for each determination. Plates were maintained at $37^{\circ} \mathrm{C}$ in a humidified atmosphere of $5 \%$ $\mathrm{CO}_{2}$ and $95 \%$ air. A 24-h preincubation time was allowed prior to addition of drugs. CDDP or Taxol were added to each well in six to eight grades. After incubation of $72 \mathrm{~h}$ with drugs, 3-(4,5-dimethylthiazol-2-yl)-2,5-dipherytetradium bromide (Sigma, St. Louis, MO, USA) solution $(100 \mu \mathrm{g})$ was added to each well and the plates were incubated at $37^{\circ} \mathrm{C}$ for $4 \mathrm{~h}$. Following incubation, $100 \mu 1$ of extraction buffer containing $20 \%$ sodium dodecyl sulfate, $50 \% \mathrm{~N}, \mathrm{~N}$-dimethylformamide, $\mathrm{pH} 7.4$ was added to each well to dissolve the formazan crystals overnight. Absorbance at $540 \mathrm{~nm}$ on each well was measured using Immunoskan 340 (Labsystems, Vantaa, Finland). Control wells for absorbance readings contained cell-free medium. All experiments were performed at least three times. Resistance index (RI) equals the ratio of the inhibitory concentration $50 \%\left(\mathrm{IC}_{50}\right)$ values of resistant to sensitive cells.

Morphological observations. For light microscopy, exponentially growing cells were transferred to $30-\mathrm{mm}$ dishes containing sterile glass slides and allowed to adhere in 5\% $\mathrm{CO}_{2}$ at $37^{\circ} \mathrm{C}$ for $24 \mathrm{~h}$. Then the cells were exposed to CDDP or Taxol for different time periods as described above. The treated cells were immediately plated in drug-free growth medium after drug treatment. Following maintainence in drug-free growth medium for $24 \mathrm{~h}$ or several days when the cells were $70-80 \%$ confluent, the slides were washed, fixed in methanol for $10 \mathrm{~min}$ and stained by the Wright-Giemsa method. For electron microscopy, the harvested cells were fixed with $3 \%$ glutaraldehyde in $0.1 \mathrm{M}$ PBS (pH 7.4) at $4^{\circ} \mathrm{C}$ for $2 \mathrm{~h}$, postfixed in $1 \%$ osmium tetroxide overnight at $4^{\circ} \mathrm{C}$, dehydrated with a graded series of acetone and embedded in Araldite, which were polymerized at $60^{\circ} \mathrm{C}$ for $48 \mathrm{~h}$. Ultrathin sections (50-80-nm) were stained with uranyl acetate and lead citrate and then observed with EM400T transmission electron microscope (Philips, Eindhoven, The Netherlands).

Growth curves. Single-cell suspensions were prepared. Aliquots containing 2,000 cells were seeded into $30-\mathrm{mm}$ dishes preloaded with $2 \mathrm{ml}$ medium. Three duplicate wells were used for each determination. Four cell counts for each replicate from each cell line were made every $24 \mathrm{~h}$ for 7 days. The data were subjected to liner regression analysis, in which the doubling time $\left(\mathrm{T}_{\mathrm{d}}\right)$ was calculated from the formula: $\mathrm{T}_{\mathrm{d}}=$ In $2 /$ slope.

Cell cycle analysis by flow cytometry. Monodispersed cells $\sim 1 \times 10^{6}$ were harvested during the exponential growth phase. The cells were washed with PBS, fixed in $70 \%$ ethanol, and stored at $-20^{\circ} \mathrm{C}$ overnight. The fixed cells were washed twice in PBS, resuspended in PBS containing $200 \mu \mathrm{g}$ RNase A (Sigma) and incubated at $37^{\circ} \mathrm{C}$ for $30 \mathrm{~min}$. The samples were stained with $20 \mu \mathrm{g}$ propidine iodide protected from light for 30 min and then analyzed on a FACS calibur (BD Company, Franklin Lakes, NJ, USA).

Semiquantitative RT-PCR. Total RNA from cells of $\sim 5 \times 10^{6}$ was isolated with TRIzol Reagent (Sigma) according to the supplier's instructions. The RNA concentration was determined 
Table I. DNA sequence of the forward and reverse primers, length of product and annealing temperature for RT-PCR.

\begin{tabular}{llcc}
\hline Primer & \multicolumn{1}{c}{ Sequence } & Length $(\mathrm{bp})$ & $\begin{array}{c}\text { Annealing } \\
\text { temperature }\left({ }^{\circ} \mathrm{C}\right)\end{array}$ \\
\hline B-actin & $\begin{array}{c}\text { ACACTGTGCCCATCTACGAGG } \\
\text { AGGGGCCGGACTCGTCATACT }\end{array}$ & 621 & 58 \\
MDR1 & CCCATCATTGCAATAGCAGG & 58 \\
GRP1 & ACCAAGACGTATCAGGTGGC & 157 & 58 \\
LRP & CTGTCAGGTTCCAGCTCCTC & 428 & 58 \\
ACAACTACTGCGTGATTCTCG & & 350 & 58 \\
& GGTCTTGACATCCTGCACATA & & 587 \\
\hline
\end{tabular}

Table II. $\mathrm{IC}_{50}$ and RI values of the resistant cell lines by pulse or intermittent method using CDDP or Taxol.

\begin{tabular}{lccr}
\hline & \multicolumn{2}{c}{$\mathrm{IC}_{50}(\mu \mathrm{M})$} \\
\cline { 2 - 3 } Cell line & CDDP & Taxol & \multicolumn{1}{c}{$\mathrm{RI}$} \\
\hline SKOV3 & $6.67 \pm 2.58$ & $80.79 \pm 10.82$ & 1.00 \\
SD-P & $27.24 \pm 8.60$ & $\mathrm{ND}$ & 4.12 \\
SD-80 & $76.07 \pm 3.85$ & $\mathrm{ND}$ & 11.50 \\
ST-P & $\mathrm{ND}$ & $328.83 \pm 58.60$ & 261.98 \\
ST-25 & $\mathrm{ND}$ & $757.46 \pm 80.85$ & 622.76 \\
\hline
\end{tabular}

$\mathrm{ND}$, the value of $\mathrm{IC}_{50}$ that was not detected.

spectrophotometrically at $260 \mathrm{~nm}$. The quality of the isolated RNA was checked by agarose gel electrophoresis by means of the presence of $28 \mathrm{~s}$ and $18 \mathrm{~s}$ rRNA. The isolated RNA was used for the preparation of first-strand cDNA by reverse transcription. The RNA samples were incubated in $20 \mu 1$ of a reaction buffer containing $10 \mathrm{mM}$ Tris- $\mathrm{HCl}(\mathrm{pH} 8.3), 50 \mathrm{mM}$ $\mathrm{KCl}, 5 \mathrm{mM} \mathrm{MgCl}_{2}, 2.5 \mathrm{pM}$ oligo dT-adaptor primer, $1 \mathrm{mM}$ dNTP each, $20 \mathrm{U}$ RNase inhibitor, and 2.5 U AMV reverse transcriptase (Takara, Japan) at $42^{\circ} \mathrm{C}$ for $60 \mathrm{~min}$. The PCR mixture of $20 \mu \mathrm{l}$ contained $10 \mathrm{mM}$ Tris- $\mathrm{HCl}$ (pH 8.3), $50 \mathrm{mM}$ $\mathrm{KCl}, 1.5 \mathrm{mM} \mathrm{MgCl}{ }_{2}, 0.25 \mathrm{mM}$ dNTP each, $1 \mathrm{U}$ Taq plus polymerase, $2.5 \mathrm{pmol}$ each of the primers and $1 \mu \mathrm{g}$ cDNA samples. The PCR conditions included an initial denaturation of $2 \mathrm{~min}$ at $95^{\circ} \mathrm{C}$, followed by 30 cycles consisting of $20 \mathrm{sec}$ denaturation at $95^{\circ} \mathrm{C}, 1 \mathrm{~min}$ primer annealing at $58^{\circ} \mathrm{C}, 50 \mathrm{sec}$ elongation at $72^{\circ} \mathrm{C}$ in PTC-150 minicycler (MJ Research, USA). A negative control using water instead of DNA was used for each PCR. The sequence of each primer and product length is shown in Table I. The resulting DNA fragments were separated by electrophoresis on a $1.5 \%$ agarose gel
A

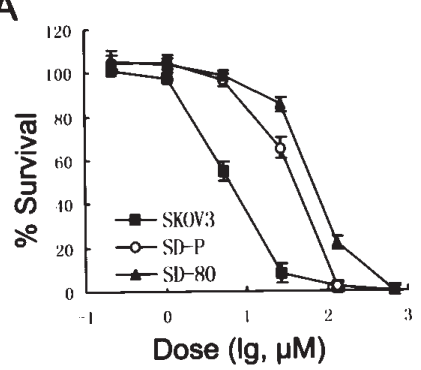

B

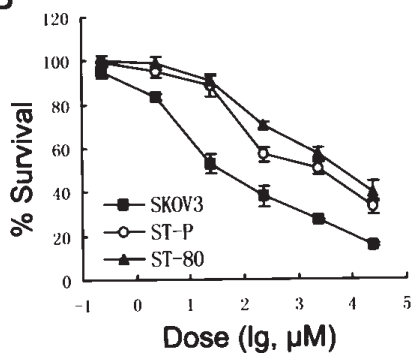

Figure 1. Survival curves determined by drug sensitivity assay for SKOV3 and its derivative CDDP- or Taxol-resistant subclones. A, survival curve for SKOV3 and its CDDP-resistant subclones. B, survival curve for SKOV3 and its Taxol-resistant subclones.

containing $0.5 \mu \mathrm{g} / \mathrm{ml}$ of ethidium bromide. Actin was used as internal standards. The band intensities were obtained by QCapturePro software and the ratio of each gene to actin was calculated.

Statistical analysis. Results were expressed as the mean \pm SD of 3-5 repeated experiments. Data analysis was carried out utilizing the SPSS12.0 statistical software package. Continuous variables were analyzed using Student's t-test. Differences between groups were considered significant at $\mathrm{P}<0.05$. The reported $\mathrm{P}$-values were two-sided.

\section{Results}

Resistant phenotype of the four sublines. We finished the establishment of CDDP-resistant and Taxol-resistant cell sublines of SKOV3 over a period of 16 months. The resultant CDDP- or Taxol-resistant sublines were then maintained and passaged in drug-free medium for at least two months. The stability of drug resistance was examined at monthly intervals. The drug sensitivity data of the five cell lines are shown in Table II and Fig. 1. The resistant phenotype was very stable because the values of $\mathrm{IC}_{50}$ and $\mathrm{RI}$ showed no significant 
A

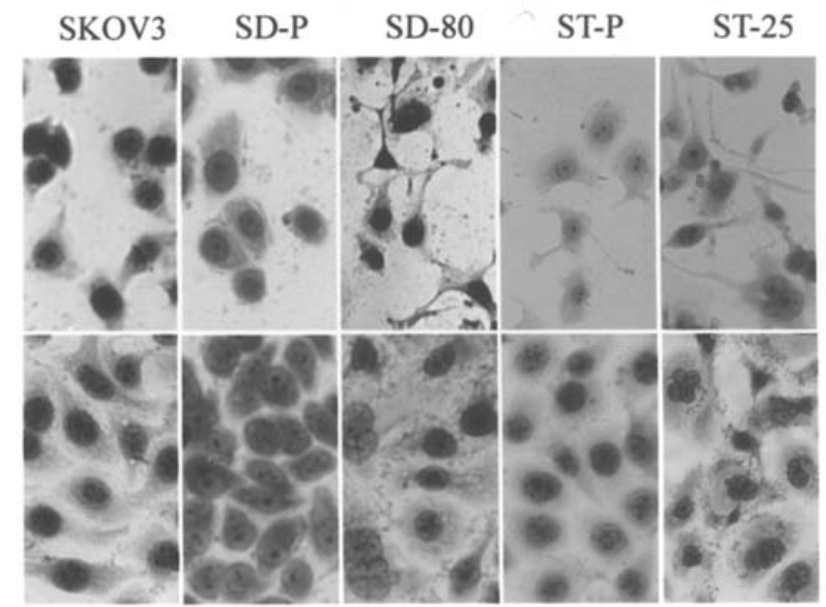

B

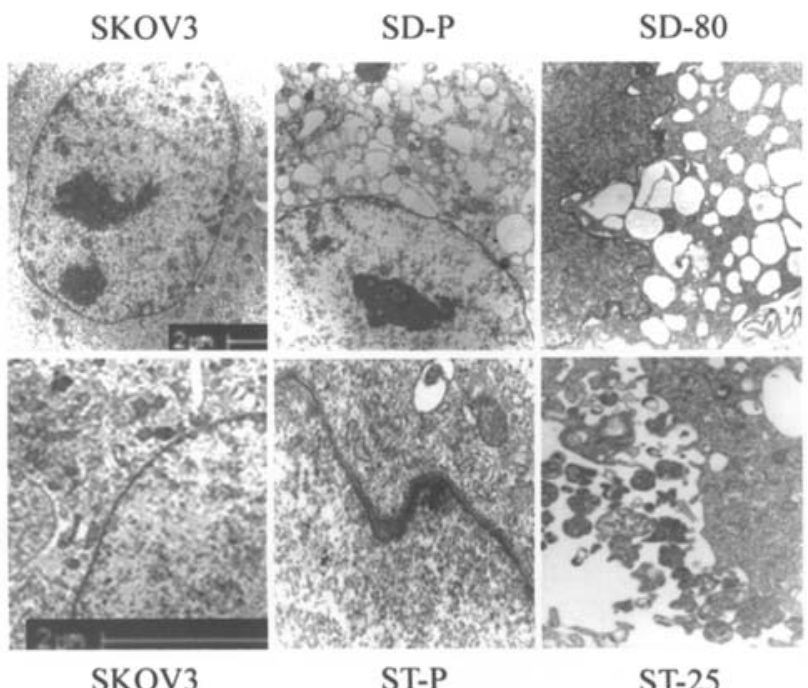

Figure 2. A, morphology of parental, cisplatin-resistant and Taxol-resistant SKOV3 cell lines by inverted microscope. The five cells treated by cisplatin or Taxol with their respective dosage (top) and their corresponding cells in exponential phase (bottom) are shown at original magnification x200. B, morphology of the five cells by transmission electron microscopy. SKOV3, SD-P and SD-80 cells (top) are shown at original magnification $\mathrm{x} 8000$. SKOV3, ST-P and ST-25 cells (bottom) are shown at original magnification $\mathrm{x} 22000$.

change during 4 months in drug-free medium (data not shown).

Morphological changes between the pulse and intermittent methods. SKOV3 showed epithelial-like shape and adhered to the disk. It had a distinct cell border and uniform cell size and shape. After exposure to CDDP or Taxol as described above, most of the cells died and cell morphology changed becoming longer and irregular in shape, varied in size, with unclear cell borders. Especially, SD-80 and ST-25 had significant changes. Most of the cells were in neuron-like shape, with some psudopodiums, and aberrant nucleus and cytosolic granules. Cell morphology gradually recovered in the logarithmic phase. There were no apparent differences

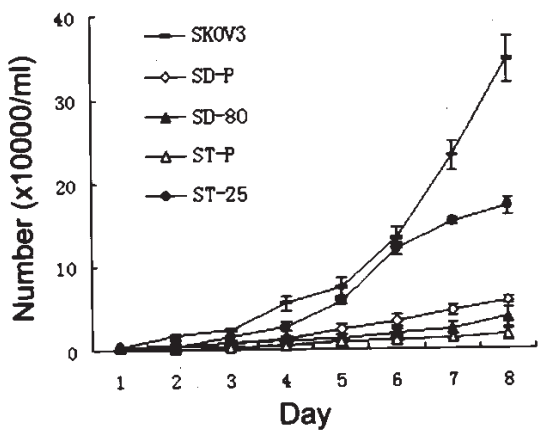

Figure 3. The cell growth curves of the human ovarian cancer cell lines SKOV3 and their drug resistant sublines SD-P, SD-80, ST-P and ST-25. Four cell counts for each replicate from each cell line were made every $24 \mathrm{~h}$ for 7 days. Cell counts using trypan blue exclusion to assess viable cells were used to determine $T_{d}$ for each cell line. $T_{d}$ was calculated as described in Materials and methods.

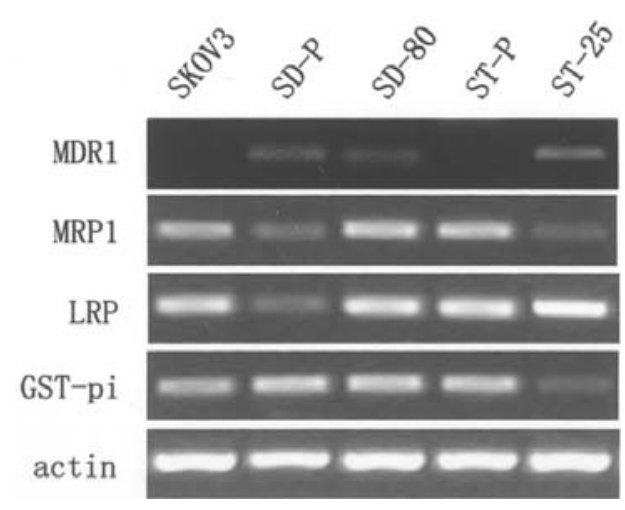

Figure 4. RT-PCR characterization of MDR1, MRP1, LRP, GST-pi in the four resistant cell lines and their parental cell line. Actin was used as internal standard.

between SKOV3 and its sublines from the pulse method by CDDP or Taxol. However, SD-80 and ST-25 were still in multiform shape, in various sizes and unclear borders (Fig. 2A). Electron microscopy of SKOV3 cells showed regular nuclei and nonuniform chromatin distribution within the nuclei. In the resistant cells, there was no significant difference between the pulse method and low-dosage intermittent inducement. The chromatin pattern of resistant cells was finely dispersed compared with SKOV3 cells, which were coarse and aggregated. The resistant cells showed expansion of mitochondria and formation of small vacuoles in cytoplasma, great amount of double membrane and pinocytic vesicles in the cell surface, and appearance of nuclear bags. Especially, SD-P and SD-80 exhibited unusually abundant vacuoles, of which some were empty, and some contained granules (Fig. 2B).

Cell growth and $T_{d}$ of five cell lines. All the five cell types were in detention phase and cell number had no significant change on the second day after seeding. SKOV3 was in logarithmic phase and cell number was much more than SD-P, SD-80 and ST-P since the third day (Fig. 3). $\mathrm{T}_{\mathrm{d}}$ of SKOV3, 
Table III. Cell cycle distribution of the five cell lines.

\begin{tabular}{lcccrr}
\hline Parameter & SKOV3 & SD-P & SD-80 & ST-P & ST-25 \\
\hline $\mathrm{G}_{0} / \mathrm{G}_{1}(\%)$ & $46.15 \pm 3.26$ & $60.74 \pm 2.36^{\mathrm{b}}$ & $65.41 \pm 3.88^{\mathrm{b}}$ & $65.04 \pm 4.01^{\mathrm{b}}$ & $59.03 \pm 2.52^{\mathrm{b}}$ \\
$\mathrm{S}(\%)$ & $40.30 \pm 2.68$ & $27.76 \pm 1.69^{\mathrm{a}}$ & $26.74 \pm 1.93^{\mathrm{b}}$ & $23.31 \pm 1.85^{\mathrm{b}}$ & $26.44 \pm 1.43^{\mathrm{b}}$ \\
$\mathrm{G}_{2} / \mathrm{M}(\%)$ & $13.55 \pm 0.59$ & $11.50 \pm 0.70^{\mathrm{a}}$ & $7.85 \pm 1.57^{\mathrm{a}}$ & ${ }^{\mathrm{c}} 11.65 \pm 0.70^{\mathrm{a}}$ & $14.53 \pm 1.26$ \\
\hline
\end{tabular}

${ }^{\mathrm{a}} \mathrm{P}<0.05,{ }^{\mathrm{b}} \mathrm{P}<0.01$ compared with SKOV3; ${ }^{\mathrm{C}} \mathrm{P}<0.05$ compared with $\mathrm{ST}-25$.

SD-P, SD-80, ST-P and ST-25 was $27.49 \pm 4.21 \mathrm{~h}, 47.26 \pm$ $4.64 \mathrm{~h}, 57.48 \pm 6.17 \mathrm{~h}, 93.13 \pm 14.01 \mathrm{~h}$ and $32.99 \pm 4.05 \mathrm{~h}$, respectively. $\mathrm{T}_{\mathrm{d}}$ of SD-P, SD-80 and ST-P was significant compared with SKOV3 $(\mathrm{P}<0.01, \mathrm{P}<0.001, \mathrm{P}<0.01)$. SD-80 that grew slowly had significant difference from SD-P in $T_{d}$ $(\mathrm{P}<0.01)$. ST-25, which grew faster than ST-P $(\mathrm{P}<0.01)$, had no significant difference in $\mathrm{T}_{\mathrm{d}}$ compared with SKOV3.

Cell cycle distribution and DNA content. Cell cycle distribution of each cell line is shown in Table III. The cells of SD-P, SD-80, ST-P and ST-25 in $\mathrm{G}_{0} / \mathrm{G}_{1}$ phase increased markedly $(\mathrm{P}<0.01)$ and the cells of SD-P and SD-80 in S phase and $\mathrm{G}_{2} / \mathrm{M}$ phase decreased significantly $(\mathrm{P}<0.05, \mathrm{P}<0.01)$. There was no statistical difference between SD-P and SD-80 in every phase of cell cycle, but SD-80 had a trend of increase in $G_{0} / G_{1}$ phase compared with SD-P. The cells of ST-P and ST-25 in S phase decreased compared with SKOV3 $(\mathrm{P}<0.01)$. ST-P cells in $\mathrm{G}_{2} / \mathrm{M}$ phase decreased compared with SKOV3 and ST-25 $(\mathrm{P}<0.05)$.

Expression of drug resistance-associated genes. The mRNA expression of MDR1, multidrug resistance protein 1 (MRP1), lung resistance protein (LRP) and GST-pi is shown in Fig. 4. MDR1 was not detected and MRP1, LRP and GST-pi could be detected in the parental SKOV3 cell line. In SD-P, MDR1 was up-regulated, MRP1 and LRP were downregulated and GST-pi had no change compared with SKOV3 and SD-80. In SD-80, the other three genes had no change except for MDR1 that was up-regulated compared with SKOV3. There was no difference between ST-P and SKOV3 in expression of four drug resistance-associated genes. Compared with SKOV3, expression of MDR1 and LRP increased, whereas expression of MRP1 and GST-pi decreased in ST-25.

\section{Discussion}

We induced two resistant sublines by CDDP and Taxol with different approaches, respectively. SD-P and ST-P was generated from pulse treatment similar to that used in the clinic with pulse dosage according to plasma peak concentration in patients. SD-80 and ST-25 was produced by conventional methods. To our knowledge, this is the first study comparing the difference of drug resistance between different methods of inducement and demonstrating the importance of the resistant cell model similar to the clinical situation in ovarian cancer. In RI values, SD-80 had a 2.8-fold increase compared with SD-P and ST-25 had a 2.4-fold increase compared with ST-P, suggesting the resistant cells selected by the intermittent method was more resistant than the cells selected by the pulse method, which was consistent with a previous study (13). From the RI data generated in the identical period, we assumed that the extent to drug resistance of pulse treatment may be more similar to the clinical chemoresistance because the observation that cells selected for resistance in vitro acquire higher levels of resistance than those observed in tumors of patients that are refractory to CDDP-based chemotherapy have been underscored (14). Some studies showed that the resistant cells needed to grow in drug-containing medium to maintain the stability of drug resistance, otherwise the characteristic of drug resistance would be lost (15). However, in our study, the resistant phenotype was very stable and the values of $\mathrm{IC}_{50}$ and RI had no significant change in 4 months in drug-free medium, suggesting the resistant sublines selected by the pulse method may serve as appropriate models for the study of mechanisms of drug resistance in ovarian cancer.

Although the changes of subcellular structure by electron microscopy were similar, the morphology by light microscopy was different between the cells selected by the pulse method and the intermittent method. SD-80 that grew more slowly had more significant changes than SD-P suggesting biological characteristics such as cell cycle and cytoskeleton regulation would appear essential changes following the development of drug resistance. However, the Taxol-resistant cells showed inconsistent changes between morphology and cell growth and proliferation compared with SKOV3. ST-P from the pulse method had no significant change in cell morphology, but proliferation index decreased significantly. On the contrary, ST-25 from intermittent treatment that had significant changes in cell morphology altered less prominently in proliferation index and cell cycle than ST-P. These results showed dissimilar dosages of inducement that affected the property of drug resistance to different degrees.

Mechanisms of resistance to CDDP and Taxol include the following aspects: 1) decreased drug accumulation; 2) increased repair of drug induced damage; 3) altered gene expression and drug target; 4) increased resistance to apoptosis $(16,17)$. The abundant vacuoles in the resistant cells by electron microscopy may contribute to drug uptake and metabolism and dysfunction to drug target, and the changes of subcellular structure such as mitochondria and membrane surface may be involved in increased protection against oxidative stress and efflux of drug, which is supported by previous observations 
(18-20). Although there were subtle differences in S phase and $\mathrm{G}_{2} / \mathrm{M}$ phase between the cells from the pulse method and from the intermittent incremental method, they all had a significant increase in $\mathrm{G}_{0} / \mathrm{G}_{1}$ phase compared with their parent cells. It may be speculated that the alteration of cell cycle arrest in $\mathrm{G}_{0} / \mathrm{G}_{1}$ phase is important to the development of drug resistance. Since MDR1, MRP1, LRP and GST-pi are known as drug resistance-associated genes relating to CDDP and Taxol, we selected the four genes for detecting differences between the pulse and intermittent methods. MRP1 and LRP displayed different expression level in the CDDP-resistant sublines induced by different treatments. The decrease of LRP in SD-P was consistent with the previous studies in vivo (21). Interestingly, the expression of each of the four genes was different between ST-P and ST-25. Overexpression of MDR1 gene causes resistance to a host of amphipathic natral products, including taxanes, vinca alkaloids, epipodophylotoxins and anthracyclines (22). Recent studies have confirmed that overexpression of MDR1 is involved in Taxol-resistance $(23,24)$. Our findings that MDR1 was not detected in ST-P and overexpressed in ST-25 showed MDR1 plays a different role in Taxol resistance selected by different methods. Up-regulation of GST-pi that catalyzes the combination of glutathione with electronphilic molecules and improves drug detoxification was regarded as one of the major reasons resulting in platinum-resistance (25). In our study, expression of GST-pi had no significant change in SD-P, SD-80, ST-P, which was similar to the study of Li et al (26). These findings also demonstrate that inconsistent conclusions have been obtained in spite of the same cell lines resistant to the same drugs. It is important to note that the same drugs but different approaches of inducement may lead to distinct expression of drug resistanceassociated genes and mechanisms of drug resistance was different for dissimilar methods of drug treatment, indicating that drug resistance is multi-factorial and underscoring the importance of studies with well defined systems. Nevertheless, it remains to be answered what the respective mechanisms of drug resistance to CDDP or Taxol using the pulse or intermittent incremental exposure are.

All the evidence in vitro suggest that dosage regimen of anti-tumor agents in clinical patients may have certain influences upon the occurrence of clinical resistant cases. The existence of complex metabolisms, microenvironment effects, epigenetic changes in vivo lead to the troubled condition for exploring mechanisms of drug resistance and reversing clinical resistance. Studies with cell lines can serve as an initial screen for agents that might modulate drug resistance and it is crucial to realize the standardization and drug-resistant models. Our study that investigated the establishment of resistant cell lines by different methods provided the basis for further movement from the laboratory to the clinic. The establishment of standardized resistant model similar to clinical resistance will be useful in the study of resistant mechanisms and reversal of clinical drug resistance.

\section{Acknowledgements}

This study was supported by the Key foundation of PUMC Hospital (Grant 200203*). We thank Dr Bing Liu for critical comments on the study and colleagues for excellent technical assistance (Department of Cell Biology, Institute of Basic Medical Sciences).

\section{References}

1. Berek JS: Epithelial ovarian cancer. In: Practical Gynecologic Oncology. Berek JS and Hacker NF (eds). Lippincott Williams \& Wilkins, Philadelphia, PA, pp457, 2000.

2. Shen K: Chemotheropy in ovarian cancer. In: Challenges and Controversies in Gynecologic Oncology. Shen K and Lang JH (eds). People's Medical Publishing House, Beijing, pp99-100, 2002.

3. Vandier D, Calvez V, Massade L, Gouyette A, Mickley L, Fojo T and Rixe O: Transactivation of the metallothionein promoter in cisplatin-resistant cancer cells: a specific gene therapy strategy. J Natl Cancer Inst 92: 642-647, 2000.

4. Godwin AK, Meister A, O'Dwyer PJ, Huang CS, Hamilton TC and Anderson ME: High resistance to cisplatin in human ovarian cancer cell lines is associated with marked increase of glutathione synthesis. Proc Natl Acad Sci USA 89: 3070-3074, 1992.

5. Liang Y, O’Driscoll L, McDonnell S, et al: Enhanced in vitro invasiveness and drug resistance with altered gene expression patterns in a human lung carcinoma cell line after pulse selection with anticancer drugs. Int J Cancer 111: 484-493, 2004.

6. Perchellet EM, Wang Y, Weber RL, et al: Synthetic 1,4-anthracenedione analogs induce cytochrome c release, caspase-9, -3 , and -8 activities, poly(ADP-ribose) polymerase- 1 cleavage and internucleosomal DNA fragmentation in HL-60 cells by a mechanism which involves caspase- 2 activation but not Fas signaling. Biochem Pharmacol 67: 523-537, 2004.

7. Roninson IB, Chin JE, Choi KG, et al: Isolation of human mdr DNA sequences amplified in multidrug-resistant KB carcinoma cells. Proc Natl Acad Sci USA 83: 4538-4542, 1986.

8. Whelan RD, Hosking LK, Townsend AJ, Cowan KH and Hill BT: Differential increases in glutathione S-transferase activities in a range of multidrug-resistant human tumor cell lines. Cancer Commun 1: 359-365, 1989.

9. Vaisman A, Varchenko M, Said I and Chaney SG: Cell cycle changes associated with formation of Pt-DNA adducts in human ovarian carcinoma cells with different cisplatin sensitivity. Cytometry 27: 54-64, 1997.

10. Brown R, Clugston C, Burns P, Edlin A, Vasey P, Vojtesek B and Kaye SB: Increased accumulation of p53 protein in cisplatinresistant ovarian cell lines. Int J Cancer 55: 678-684, 1993.

11. Herod JJ, Eliopoulos AG, Warwick J, Niedobitek G, Young LS and Kerr DJ: The prognostic significance of Bcl-2 and p53 expression in ovarian carcinoma. Cancer Res 56: 2178-2184, 1996.

12. Di Leo A, Bajetta E, Biganzoli L, et al: An I.T.M.O. group study on second-line treatment in advanced epithelial ovarian cancer: an attempt to identify clinical and biological factors determining prognosis. Eur J Cancer 31A: 2248-2254, 1995.

13. Yang LY and Trujillo JM: Biological characterization of multidrug-resistant human colon carcinoma sublines induced/ selected by two methods. Cancer Res 50: 3218-3225, 1990.

14. Enns RE and Howell SB: Isolation of a gene associated with resistance to cisplatin. In: Platinum and Other Metal Coordination Compounds in Cancer Chemotherapy. Howell SB (ed). Plenum Press, New York, pp213-220, 1991.

15. Twentyman PR, Fox NE, Wright KA and Bleehen NM: Derivation and preliminary characterisation of adriamycin resistant lines of human lung cancer cells. Br J Cancer 53: 529-537, 1986.

16. Kartalou M and Essigmann JM: Mechanisms of resistance to cisplatin. Mutat Res 478: 23-43, 2001.

17. Sangrajrang $S$ and Fellous A: Taxol resistance. Chemotherapy 46: 327-334, 2000.

18. Dvorakova K, Payne CM, Tome ME, et al: Molecular and cellular characterization of imexon-resistant RPMI8226/I myeloma cells. Mol Cancer Ther 1: 185-195, 2002.

19. Meijera C, van Luyn MJ, Nienhuis EF, Blom N, Mulder NH and de Vries EG: Ultrastructural morphology and localisation of cisplatin-induced platinum-DNA adducts in a cisplatinsensitive and -resistant human small cell lung cancer cell line using electron microscopy. Biochem Pharmacol 61: 573-578, 2001 . 
20. Mazzoni A, Trave F, Russo P, Nicolin A and Rustum YM: Generation and characterization of a low-degree drug-resistant human tumor cell line. Oncology 47: 488-494, 1990.

21. Kolfschoten GM, Hulscher TM, Pinedo HM and Boven E: Drug resistance features and S-phase fraction as possible determinants for drug response in a panel of human ovarian cancer xenografts. Br J Cancer 83: 921-927, 2000.

22. Gottesman MM: How cancer cells evade chemotherapy: sixteenth Richard and Hinda Rosenthal Foundation Award Lecture. Cancer Res 53: 747-754, 1993.

23. Schondorf T, Kurbacher C, Gohring U, et al: Induction of MDR1-gene expression by antineolastic agents in ovarian cancer cell lines. Anticancer Res 22: 2199-2203, 2002.
24. Di Nicolantonio F, Knight LA, Whitehouse PA, et al: The ex vivo characterization of XR5944 (MLN944) against a panel of human clinical tumor samples. Mol Cancer Ther 3: 1631-1637, 2004.

25. Cullen KJ, Newkirk KA, Schumaker LM, Aldosari N, Rone JD and Haddad BR: Glutathione S-transferase pi amplification is associated with cisplatin resistance in head and neck squamous cell carcinoma cell lines and primary tumors. Cancer Res 63: 8097-8102, 2003.

26. Li L, Luan Y, Wang G, et al: Development and characterization of five cell models for chemoresistance studies of human ovarian carcinoma. Int J Mol Med 14: 257-264, 2004. 